\title{
Worldwide interlaboratory study on the determination of ochratoxin A in different wine type samples
}

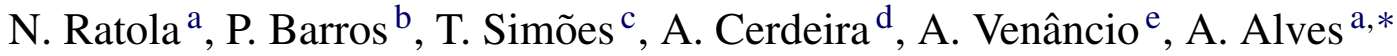 \\ ${ }^{a}$ LEPAE, Departamento de Engenharia Química, Faculdade de Engenharia da Universidade do Porto, Rua Dr. \\ Roberto Frias, 4200-465 Porto, Portugal \\ ${ }^{\mathrm{b}}$ IVV, Instituto da Vinha e do Vinho, Rua de Serpa Pinto 571-1, 4400-307 Vila Nova de Gaia, Portugal \\ ${ }^{\mathrm{c}}$ IVDP, Instituto dos Vinhos do Douro e Porto, Rua de Ferreira Borges 27, 4050-253 Porto, Portugal \\ ${ }^{\mathrm{d}}$ CVRVV, Comissão de Viticultura da Região dos Vinhos Verdes, Rua da Restauração 318, 4050-501 Porto, Portugal

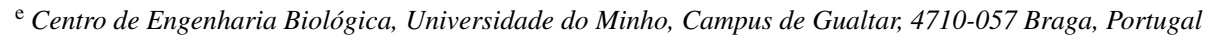

Received 15 January 2006; received in revised form 8 May 2006; accepted 17 May 2006

Available online 3 July 2006

\begin{abstract}
Interlaboratory studies are decisive tools to help the validation of a specific analytical methodology or to assess the reproducibility of the use of different methods to analyze a given compound or compounds in certain sample matrices. In this work, homogeneous samples of two white wines ("White Wine" and "White Liqueur Wine") and one red wine ("Red Fortified Wine") from Portugal with different production techniques and characteristics, namely in alcohol strength $(10.5 \%, 16.0 \%$ and $19.0 \%$ ethanolic content, respectively), were analyzed for their contents in ochratoxin A (OTA), a mycotoxin generated from fungal contamination. White Liqueur Wine was naturally contaminated, whereas the other two wine type were spiked with ethanolic OTA solutions. The participation of 24 laboratories from 17 countries of five continents was ensured for this study. Although with no restrictions in terms of analytical methodology to employ, $75 \%$ of the laboratories resorted to immunoaffinity columns clean-up followed by high performance liquid chromatography with fluorescence detection (HPLC-FD), most of them in accordance with the European Standard EN 14133. For White Wine samples, the general mean OTA concentration was $1.96 \mu \mathrm{g} / 1$ (two outliers) with interlaboratorial standard deviation $\left(s_{\mathrm{L}}\right)$ of $0.53 \mu \mathrm{g} / \mathrm{l}$; for White Liqueur Wine, mean of $1.59 \mu \mathrm{g} / \mathrm{l}$ (one outlier), with $s_{\mathrm{L}}=0.59 \mu \mathrm{g} / \mathrm{l}$; and for Red Fortified Wine, mean of $2.73 \mu \mathrm{g} / \mathrm{l}$ (no outliers), with $s_{\mathrm{L}}=0.96 \mu \mathrm{g} / \mathrm{l}$. Outliers were determined by Cochran and Grubbs tests. The Horrat index, recommended by the Association of Official Analytical Chemists (AOAC) for the quality assurance of the collaborative study was, on average, 1.7. This study proved that OTA determination in wines is reproducible, regardless of the methodology employed.
\end{abstract}

(C) 2006 Elsevier B.V. All rights reserved.

Keywords: Ochratoxin A; Wines; Interlaboratory study; $z$-Scores; Outliers

\section{Introduction}

Ochratoxin A (OTA) is a mycotoxin (fungal contaminationderived metabolites) produced by strains of Aspergillus and Penicillium, and recently detected in several food matrices, including alcoholic beverages. Since first reported in wines by Zimmerli and Dick in 1995 [1], the pressure for seeking food safety urged OIV to recommend a maximum limit of $2 \mu \mathrm{g} / \mathrm{l}$ for safe intake in wines [2]. The European Union recently adopted the value of $2.0 \mu \mathrm{g} / \mathrm{kg}$ as maximum residue level of OTA for wine (red, white and rosé) [3]. OTA has been classified as pos-

\footnotetext{
* Corresponding author. Tel.: +35122 5081883; fax: +351225081449.

E-mail address: aalves@ fe.up.pt (A. Alves).
}

sessing nephrotoxic, carcinogenic, teratogenic, genotoxic and immunotoxic properties [4], amongst other hazardous effects. The main problem is that the routes of OTA intake for humans come from several food sources rather than from a specific acute one. Nevertheless, various data have been published in literature reporting OTA levels in wines ranging from a few nanograms to several micrograms per litre worldwide [5-18].

Different analytical methodologies have been proposed for OTA screening, mainly comprising liquid-liquid or immunoaffinity extraction steps, previous to liquid chromatographic analysis with fluorescence detection (HPLC-FD) $[19,20]$. Other detection methods used include mass spectrometry (MS/MS) $[19,21]$ and photodiode array detection (PDA) [17]. Different clean-up procedures such as anion exchange [22] and molecular imprinted polymers (MIP) [23] were also 
recently reported. A reference method has been approved in 2003 by the European Committee for Standardization (CEN)—EN 14133 [24]. In general, immunoaffinity columns are recommended as clean-up procedure of OTA from wines and beers, prior to HPLC-FD analysis. The official method adopted by the Association of Official Analytical Chemists (AOAC) is also based on these techniques [25].

Interlaboratory studies aiming the validation of the reference method or focusing on proficiency objectives (ring-tests) have been performed for wine matrices, especially when alcoholic contents round up to $12 \%(\mathrm{v} / \mathrm{v})$.

A proficiency test has been conducted on FTIR wine analysis with the participation of six laboratories [26]. The wine sample had an average $12 \%$ in alcohol strength. Reproducibility was evaluated for several analytical determinations such as density, ethanolic content, dry extract, total sugars, total acidity, $\mathrm{pH}$, and total polyphenolic index. An interlaboratory study featuring six laboratories compared the determination of ethyl carbamate in alcoholic beverages (red, white and fortified wines, brandy and wine spirit) by HPLC-FLD and GC-MS [27].

The European Standard EN 14133:2003 reports the results of an interlaboratory test according to AOAC guidelines for collaborative study procedures to validate characteristics of a method of analysis for OTA quantification in wines [24]. The study was conducted in 1999, with the participation of 16 laboratories, strictly applying the aforementioned standard. There is no information concerning the type of wines analysed, apart from the citation that the samples were white wine, red wine or beer, spiked at three concentration levels around $0.1-0.2 \mathrm{ng} / \mathrm{ml}$, $0.9-1.1 \mathrm{ng} / \mathrm{ml}$ and $2.0-3.0 \mathrm{ng} / \mathrm{ml}$, and one naturally contaminated sample (mean concentration of $0.283 \mathrm{ng} / \mathrm{ml}$ for white wine and $1.690 \mathrm{ng} / \mathrm{ml}$ for red wine).

The Bureau InterProfessionnel d'Etudes Analytiques (BIPEA) periodically organizes proficiency tests on several wine determinations, following ISO Guide 43:1997 [28]. It is probably the organization that covers a wider range of wine types [29]. For physico-chemical analysis, red wines, dry white wines, sparkling wines, dessert wines, rosé wines, aromatized wines have been included. Contaminants such as pesticides and mycotoxins are among the determinations. However, statistical reports are sent to the participating laboratories and therefore no statistical data is divulged.

Other matrices of study and reference materials were also reported in literature as a target for similar interlaboratory collaborations, such as sewage sludge [30], wastewater [31], water [32], saliva [33], ambient air [34], plants [35] or other food products [36-38]. A review on interlaboratory studies applied to analytical chemistry aiming their different purposes and evaluation methods was published by Hund et al. [39].

The importance of such interlaboratory studies, beyond the validation of an analytical method, is nowadays seen as an important contribution to the estimation of the global uncertainty associated to the results. Concerning the complex nature of many modern methods of analysis, proficiency testing schemes allowing laboratory specific standard operating procedures (SOPs), are more to the point than method-evaluating schemes like ISO 5725:1994 [40]. Several authors describe the calculation of the uncertainty with the inclusion of the interlaboratory variability [41-44].

In view of these foundations, in this work it is proposed to study three different wine matrices, which have undergone dissimilar vinification processes and therefore having different alcohol strength:

- Red Fortified Wine and White Liqueur Wine, in which fermentation is arrested before completion by alcohol distillate addition, allowing sugar and alcohol content to be higher (around $150 \mathrm{~g} / \mathrm{l}$ total sugars and 18-19\% alcohol strength $(\mathrm{v} / \mathrm{v}))$.

- White Wine, in which fermentation is complete, thus having lower sugar and alcoholic content (less than $0.3 \mathrm{~g} / \mathrm{l}$ sugars and $9 \%$ alcohol strength). In the specific case of these samples, the acidity is slightly higher than in common table wines.

Being aware of the importance of interlaboratory studies to assess the fiability of OTA determination methods in alcoholic beverages, two Portuguese entities, LEPAE-Process Engineering, Environment and Energy Laboratory (a research group from the Faculty of Engineering of the University of Porto, FEUP) and ALABE, an Association of the Laboratories of Enology, organised such a study. ALABE acted as the guarantee of confidentiality of the process and LEPAE/FEUP performed all statistical treatment of data.

\section{Experimental}

\subsection{Organization of the study}

The main steps of this Interlaboratory Study are presented in Table 1.

\subsection{Samples analyzed}

The study was designed to comprise different types of wines and different levels of OTA contamination, both natural and spiked. As aforementioned, three different wines were chosen. In order for the participating laboratories to analyze all samples in triplicate, the necessary amount of each sample was sent, varying from $250 \mathrm{ml}$ to $750 \mathrm{ml}$, according to the requirements of the methodologies employed by the different participants. Spiking was done with $9 \%$ and $18 \%$ ethanolic solutions of OTA.

Table 1

Steps of the ochratoxin A (OTA) interlaboratory study

\begin{tabular}{lll}
\hline Step & Action & Time frame \\
\hline 1 & Last call for participants & May 2004 \\
2 & Setting of participating entities & May-June 2004 \\
3 & Samples preparation & June 2004 \\
4 & Samples delivery & June 2004 \\
5 & Experimental analysis & June-October 2004 \\
6 & Reception of the results & June-October 2004 \\
7 & Statistic analysis & November 2004 \\
8 & Final report/presentation of the results & December 2004 \\
\hline
\end{tabular}


Table 2

Participating laboratories and responsible, sorted alphabetically by country

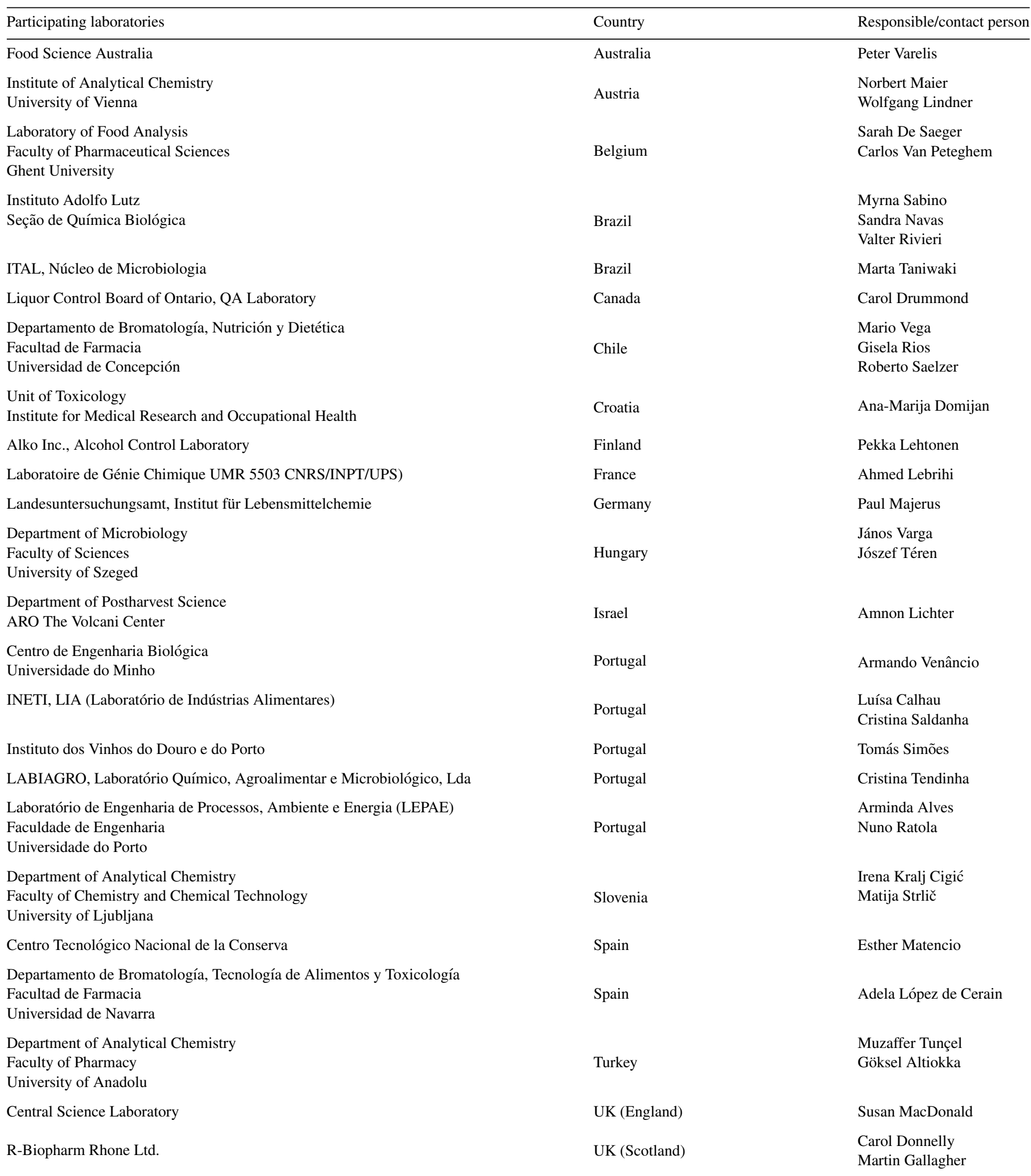


The spiked amounts were targeted to the vicinity of the OIV recommended limit.

\subsection{Participating institutions}

Following the Call for Participants, 24 entities from all over the world kindly presented their will to contribute to this study. The list of the participating laboratories is presented in Table 2.

\subsection{Analytical methods employed}

As the purpose of this study was not the validation of a given method, several analytical procedures were employed by the different laboratories to analyze the content of OTA in the wine samples. The initially proposed method was the reference method described by the European Standard EN 14133 [24], but the participants were free to choose another. The important thing to notice is the principles of the method, rather than the specific nuances of minor differences in operating values. In this case, the reference method basically consists in the dilution of the wine samples with a solution containing polyethylene glycol (PEG) and sodium hydrogen carbonate, followed by filtration and clean-up by immunoaffinity columns (IAC). OTA is eluted with methanol and quantified by reversed-phase HPLC (mobile phase: water-acetonitrile-acetic acid, 99:99:2) with fluorescence detection (FD) at $333 \mathrm{~nm}$ (excitation) and $460 \mathrm{~nm}$ (emission). This method was chosen by $50 \%$ of the partici- pants. Another $25 \%$ employed the same principle, only using a phosphate buffer solution (PBS) instead of PEG. One of the participants using this method quantified at $225 \mathrm{~nm}$ (emission). The remaining six laboratories used somewhat different procedures. Table 3 indicates the methods employed and the number of laboratories using them, with some remarks when major modifications to the EN 14133 strategy were made.

\subsection{Statistic analysis}

The statistic analysis of the results, namely the detection and elimination of outliers, the precision parameters evaluation (repeatability and reproducibility), means and $z$-scores were based in the standard ISO 5725:1994 [40], the Guide ISO 43:1997 [28] and the Guide EURACHEM "Use and interpretation of proficiency testing (PT) schemes by laboratories" [45] and comprised several steps now detailed.

\subsubsection{Assessment of consistency and outliers}

This procedure was done to find out and deal with the presence of inconsistent values, outliers or other irregularities. Global mean and respective confidence interval (at 95\%) were calculated for each level and parameter for all laboratories before the scrutiny for outliers, performed by numerical tests. First, an upper-tail Cochran test is repeatedly performed, for the comparison of the interlaboratory variances, and consequent elimination of laboratories with interlaboratory variability significantly

Table 3

Methodologies employed by the laboratories in the analyses of OTA

\begin{tabular}{|c|c|c|}
\hline Method employed & Number of laboratories & Remarks \\
\hline EN 14133 PEG-IAC-HPLC/FD) & 12 & \\
\hline PBS-IAC-HPLC/FD & 6 & $\begin{array}{l}\text { PBS, phosphate buffer solution } \\
\text { One lab at } 225 \mathrm{~nm} \text { (emission) }\end{array}$ \\
\hline & & SPE, solid-phase extraction \\
\hline SPE-HPLC/FD & 2 & $\begin{array}{l}\text { One lab using octadecylsilyl (ODS) cartridges for extraction; quantification at } 385 \mathrm{~nm} \\
\text { (emission) with reverse-phase Ultracarb(30) column; mobile phase } 1 \% \text { acetic acid in } \\
50 \% \text { aqueous acetonitrile ( } 0.65 \mathrm{ml} / \mathrm{min} \text { flowrate); } \mathrm{pH} \text { of column effluent adjusted to } 11 \text {; } \\
\text { injection volume: } 50 \mu \mathrm{L} \\
\text { One lab determined OTA with } 3 \text { standard additions; Hypersil ODS } 5 \text { column; injection } \\
\text { volume: } 20 \mu \mathrm{L} \\
\text { MIP, molecular imprinted polymer }\end{array}$ \\
\hline MIP-SPE-HPLC/FD & 1 & $\begin{array}{l}\text { First } 1 \mathrm{ml}-\mathrm{RP}-\mathrm{SPE} \text { cartridge }(100 \mathrm{mg}) \text { and then SPE cartridge packed with OTA-specific } \\
\text { MIP }(100 \mathrm{mg}) \\
\text { Reverse-phase HPLC with Synergy Max-RP } 80 \mathrm{~A} \text { column; mobile phase: } \\
\text { water/methanol/acetic acid }(57: 43: 2, \mathrm{v} / \mathrm{v} / \mathrm{v}) \text { at } 0.80 \mathrm{ml} / \mathrm{min} \text {; injection volume: } 50 \mu \mathrm{L}\end{array}$ \\
\hline SPE-HPLC/PDA & 1 & $\begin{array}{l}\text { PDA, photo diode array } \\
\text { SPE with C18 cartridges and quantification with } \mathrm{C} 18 \text { column }\end{array}$ \\
\hline DI-IS-HPLC & 1 & $\begin{array}{l}\text { DI, direct injection } \\
\text { IS, internal standard (diflunisal) } \\
\text { Direct injection of samples after addition of diflunisal; C18 column with mobile phase } \\
\text { acetonitrile/water/acetic acid ( } 40: 60: 1, \mathrm{v} / \mathrm{v} / \mathrm{v}) \text { at } 0.4 \mathrm{ml} / \mathrm{min}\end{array}$ \\
\hline SAX-LC/MS-MS & 1 & $\begin{array}{l}\text { SAX, strong anion exchange columns } \\
\text { Elution with } 5 \mathrm{ml} \text { ethylacetate ( } 1 \% \text { formic acid) } \\
\text { MS, mass spectrometry detection } \\
\text { Triple quadrupole MS operating in positive electrospray ionization with multiple reaction } \\
\text { monitoring; Alltima C18 column; mobile phase: gradient mixtures of } 0.3 \% \text { formic acid in } \\
\text { acetonitrile and } 0.3 \% \text { formic acid in water; injection volume: } 20 \mu \mathrm{L}\end{array}$ \\
\hline
\end{tabular}


superior to the mean (within laboratory consistency). Grubbs tests for single and double outliers are then applied to check if there are laboratories with means significantly different from the remaining, and eliminate them (between-laboratory variability). Care was taken as to rule out only a number of laboratories up to $2 / 9$ of the total, meaning not more than 5 in this study, for each of the three samples analyzed.

Cochran test is unilateral, once only the laboratories with variability above the mean are ruled out, and not the ones below [46]. The Grubbs tests allow the detection of anomalous mean values and are performed using the values retained from the within-laboratory consistency evaluation. In the case of the single outlier test, the occurrence of one outlying result, either the smallest or the largest, is evaluated [46].

As always throughout this study, laboratories with stragglers were maintained, whereas laboratories with outliers were ruled out.

\subsubsection{Evaluation of precision and general mean}

After the elimination of outliers for each wine sample type, values for general mean, $\hat{m}$, and variances $S_{\mathrm{L}}^{2}$ (interlaboratory), $S_{\mathrm{r}}^{2}$ (repeatability) and $S_{\mathrm{R}}^{2}$ (reproducibil- ity), were calculated according to standard ISO 5725:1994 [40].

\subsubsection{Evaluation of laboratory performance (z-scores)}

Considering all participant laboratories and to have an indication on their performance on this study, $z$-scores were calculated [40] and graphically displayed for each of the three different sample types.

\section{Results and discussion}

The organisation of the interlaboratory study results was planned to emphasise the comparison of the values obtained by the 24 participant laboratories, for the analysis of OTA in the three types of wine samples conveyed (White Wine, White Liqueur Wine and Red Fortified Wine). The confidentiality of the results was assured by ALABE.

Following the elimination of outliers, the parameters for precision, the means and respective standard deviations in the OTA quantification were calculated for each sample type. Individual and mean results are presented for each laboratory considered for each sample type, as well as the stan-

Table 4

Statistical parameters regarding OTA quantification, for White Wine samples (spiked)

\begin{tabular}{|c|c|c|c|c|c|c|c|c|}
\hline Laboratory & $\begin{array}{l}\text { Assay } 1 \\
(\mu g / 1)\end{array}$ & $\begin{array}{l}\text { Assay } 2 \\
(\mu g / 1)\end{array}$ & $\begin{array}{l}\text { Assay } 3 \\
(\mu g / 1)\end{array}$ & Method & Mean $(\mu g / 1)$ & $\begin{array}{l}\text { Standard } \\
\text { deviation }\end{array}$ & $z$-Score & Outlier \\
\hline 1 & 2.19 & 2.40 & 2.52 & EN 14133 & 2.37 & 0.17 & 0.8 & \\
\hline 2 & 2.27 & 2.30 & 2.29 & SPE-HPLC/FD & 2.29 & 0.02 & 0.6 & \\
\hline 3 & 2.10 & 2.04 & 2.07 & MIP-SPE-HPLC/FD & 2.07 & 0.03 & 0.2 & \\
\hline 4 & 9.85 & 8.56 & 8.50 & PBS-IAC-HPLC/FD & 8.97 & 0.76 & 12.8 & Cochran \\
\hline 5 & 1.60 & 1.66 & 1.42 & EN 14133 & 1.56 & 0.12 & -0.7 & \\
\hline 6 & 4.43 & 4.48 & 4.18 & EN 14133 & 4.36 & 0.16 & 4.4 & Grubbs \\
\hline 7 & 2.70 & 2.70 & 2.50 & EN 14133 & 2.63 & 0.12 & 1.2 & \\
\hline 8 & 2.70 & 2.70 & 2.70 & EN 14133 & 2.70 & 0.00 & 1.4 & \\
\hline 9 & 2.49 & 2.51 & 2.20 & EN 14133 & 2.40 & 0.17 & 0.8 & \\
\hline 10 & 1.70 & 1.70 & 1.90 & PBS-IAC-HPLC/FD & 1.76 & 0.12 & -0.3 & \\
\hline 11 & 2.07 & 1.71 & 2.15 & EN 14133 & 1.98 & 0.23 & 0.0 & \\
\hline 12 & 1.64 & 1.59 & 1.65 & DI-IS-HPLC & 1.63 & 0.03 & -0.6 & \\
\hline 13 & 1.11 & 1.09 & & PBS-IAC-HPLC/FD & 1.10 & 0.01 & -1.6 & \\
\hline 14 & 2.13 & 2.23 & 2.00 & EN 14133 & 2.12 & 0.11 & 0.3 & \\
\hline 15 & 1.70 & 1.64 & 1.73 & PBS-IAC-HPLC/FD & 1.69 & 0.05 & -0.5 & \\
\hline 16 & 0.80 & 0.80 & 1.00 & PBS-IAC-HPLC/FD & 0.87 & 0.12 & -2.0 & \\
\hline 17 & 1.53 & 1.51 & 1.35 & PBS-IAC-HPLC/FD & 1.46 & 0.10 & -0.9 & \\
\hline 18 & 2.50 & 2.45 & 2.46 & EN 14133 & 2.47 & 0.03 & 0.9 & \\
\hline 19 & 1.93 & 1.82 & 1.63 & SAX-LC/MS-MS & 1.79 & 0.15 & -0.3 & \\
\hline 20 & 1.52 & 1.56 & 1.42 & SPE-HPLC/PDA & 1.50 & 0.07 & -0.8 & \\
\hline 21 & 1.53 & 1.29 & 1.90 & EN 14133 & 1.57 & 0.31 & -0.7 & \\
\hline 22 & 2.58 & 2.60 & 2.60 & EN 14133 & 2.59 & 0.01 & 1.2 & \\
\hline 23 & 3.00 & 2.60 & 2.90 & SPE-HPLC/FD & 2.83 & 0.21 & 1.6 & \\
\hline 24 & 1.56 & 1.60 & 1.76 & EN 14133 & 1.64 & 0.11 & -0.6 & \\
\hline & & & & Accepted laboratories & \multicolumn{4}{|c|}{22 out of 24} \\
\hline & & & & General mean & \multicolumn{4}{|c|}{1.96} \\
\hline & & & & Standard deviation of the general mean & \multicolumn{4}{|c|}{0.53} \\
\hline & & & & Relative standard deviation $(\%)$ & \multicolumn{4}{|c|}{27.30} \\
\hline & & & & Maximum value (accepted laboratories) & \multicolumn{4}{|c|}{2.83} \\
\hline & & & & Minimum value (accepted laboratories) & \multicolumn{4}{|c|}{0.87} \\
\hline & & & & $s_{\mathrm{L}}$ (interlaboratorial standard deviation) & \multicolumn{4}{|c|}{0.53} \\
\hline & & & & $s_{\mathrm{r}}$ (repeatability standard deviation) & \multicolumn{4}{|c|}{0.13} \\
\hline & & & & $s_{\mathrm{R}}($ reproducibility standard deviation) & \multicolumn{4}{|c|}{0.55} \\
\hline
\end{tabular}


Z-scores White Wine 10,5\% (v/v)

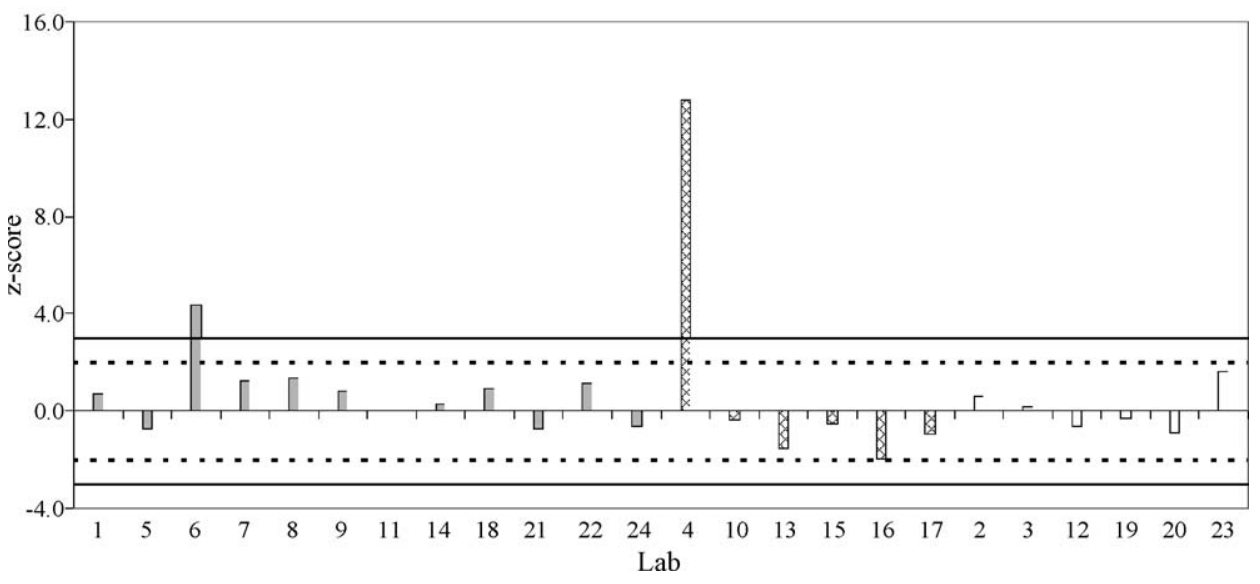

Fig. 1. $z$-Scores White Wine $10.5 \%$ (v/v).

dard deviation of means and respective performance indicator ( $z$-score). Other parameters displayed comprise the global mean, relative and absolute standard deviation for the different samples, variances (interlaboratorial, repeatability and reproducibility), as well as maximum and minimum values.

\subsection{White Wine $(10.5 \%, v / v)$}

Table 4 shows the different statistical parameters for all laboratories, for White Wine samples. Outliers are also referred, and the test used to assess them.

As can be seen, two laboratories were excluded in this case, and the general mean of the accepted ones was $1.96 \mu \mathrm{g} / \mathrm{l}$, with relative standard deviation (R.S.D.) of $27.3 \%$.

Fig. 1 depicts the $z$-scores for all laboratories. Notice that, unlike Table 4, results are divided by three different groups of methods. Grey columns represent EN 14133 (12 labs), crossed columns stand for PBS-IAC-HPLC/FD (6 labs) and finally, the remaining methods were joined in another group, named "other methods" (white columns,
6 labs). Furthermore, the mean $(2.35 \mu \mathrm{g} / \mathrm{l})$ and the confidence intervals are referred to all participants, before outlier tests.

As expected, the outliers (labs 4 and 6) show the worst results and are considered incorrect according to the $z$-scores test. There seems to be no clear relation between the results and the methods employed. Only with some effort, and before the outlier tests, the most deviant results can be globally attributed to the PBSIAC-HPLC/FD group.

When removing the outliers, the mean values match the parameters of Table 4 above, and it is noticeable in Fig. 2 that EN 14133 laboratories produce the highest percentage of results outside the confidence intervals. Considering the individual mean of each of the three groups, the PBS-IAC-HPLC/FD has the most deviant behaviour comparing to the general mean $(-29.8 \%)$, followed by the EN $14133(+11.5 \%)$ and the other methods $(+3.0 \%)$.

The relative standard deviation for reproducibility $(27.3 \%)$ was slightly higher than the $14.3 \%$ published in the European Standard 14133 for white wines [24], probably because several alterations or completely different analyti-

White Wine 10,5\%(v/v) - Accepted Labs (22)

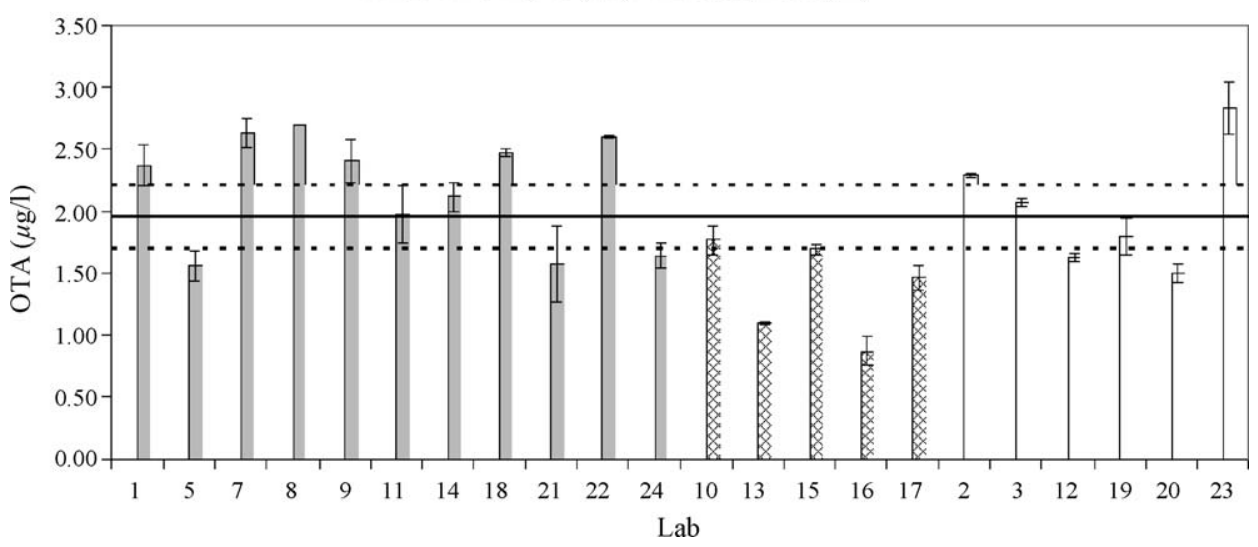

Fig. 2. White Wine $10.5 \%(\mathrm{v} / \mathrm{v})$ - accepted labs (22). 
Table 5

Statistical parameters regarding OTA quantification, for White Liqueur Wine samples

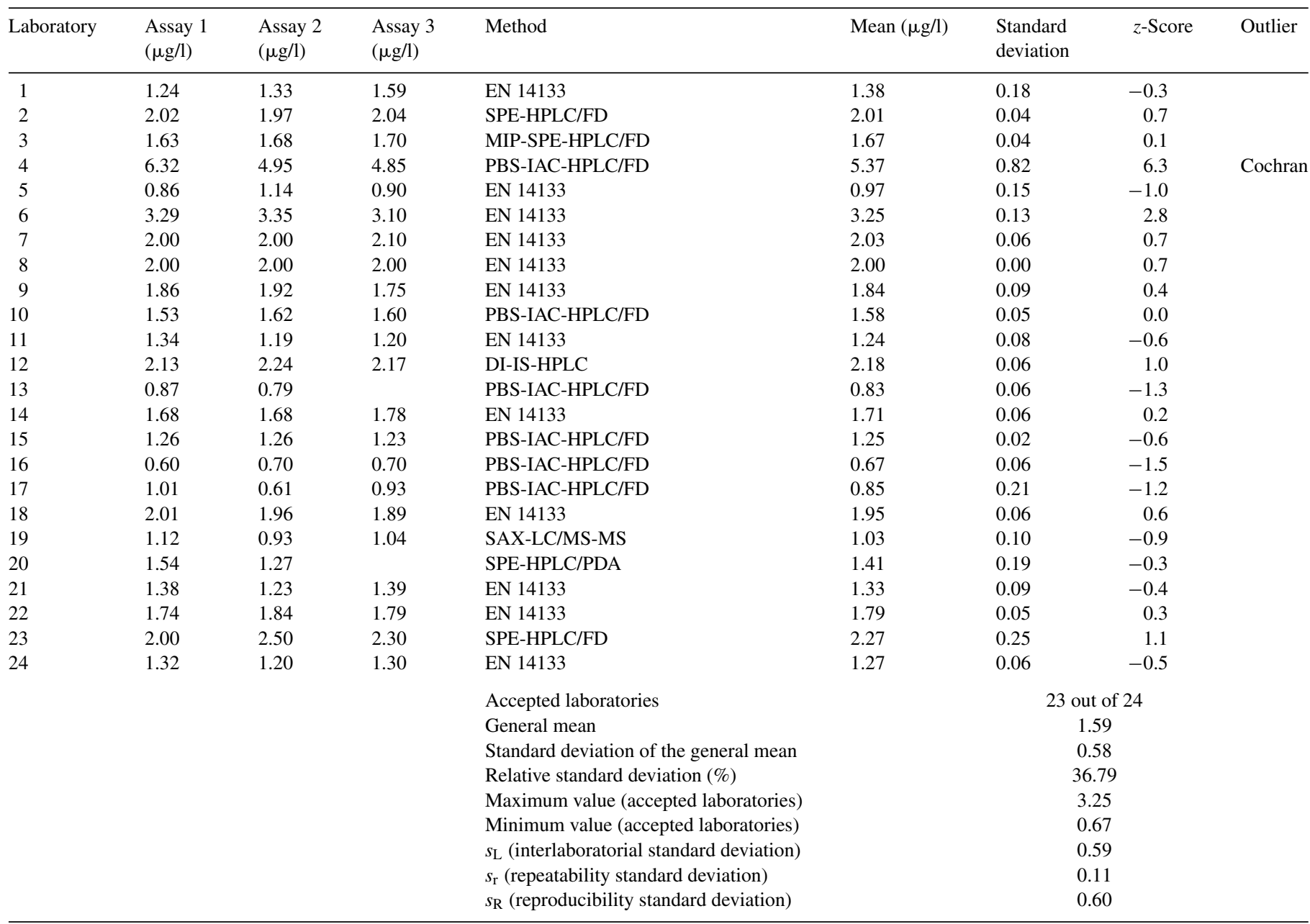

Z-score White Liqueur Wine 16\% (v/v)

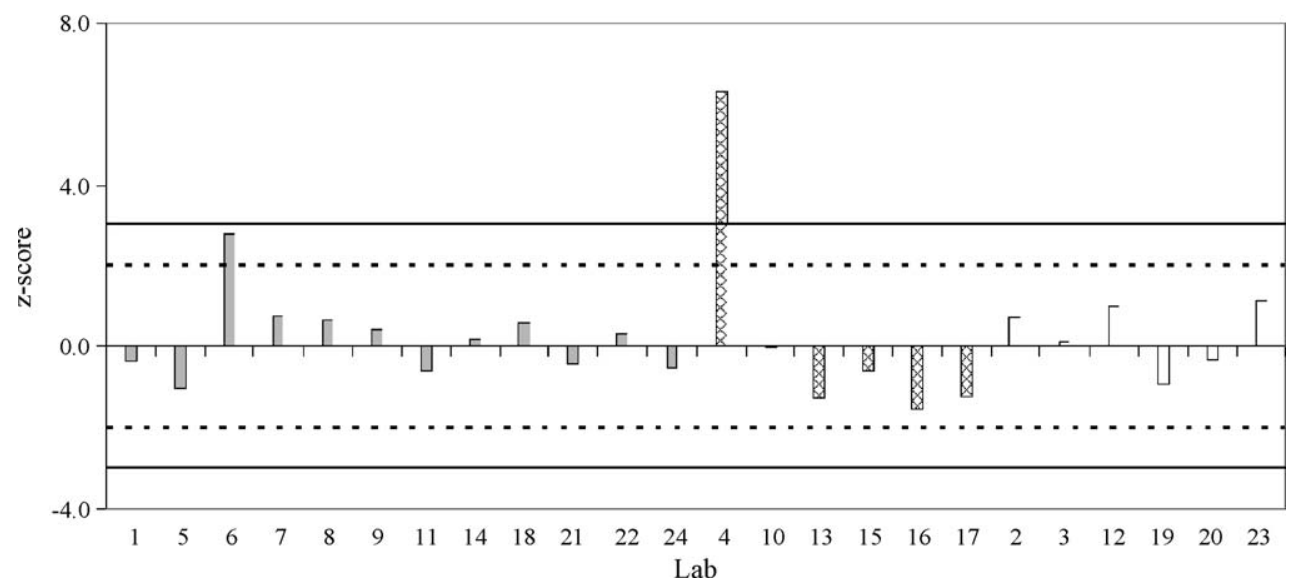

Fig. 3. z-Scores White Liqueur Wine 16\% (v/v). 
White Liqueur Wine 16\% (v/v) - Accepted Labs (23)

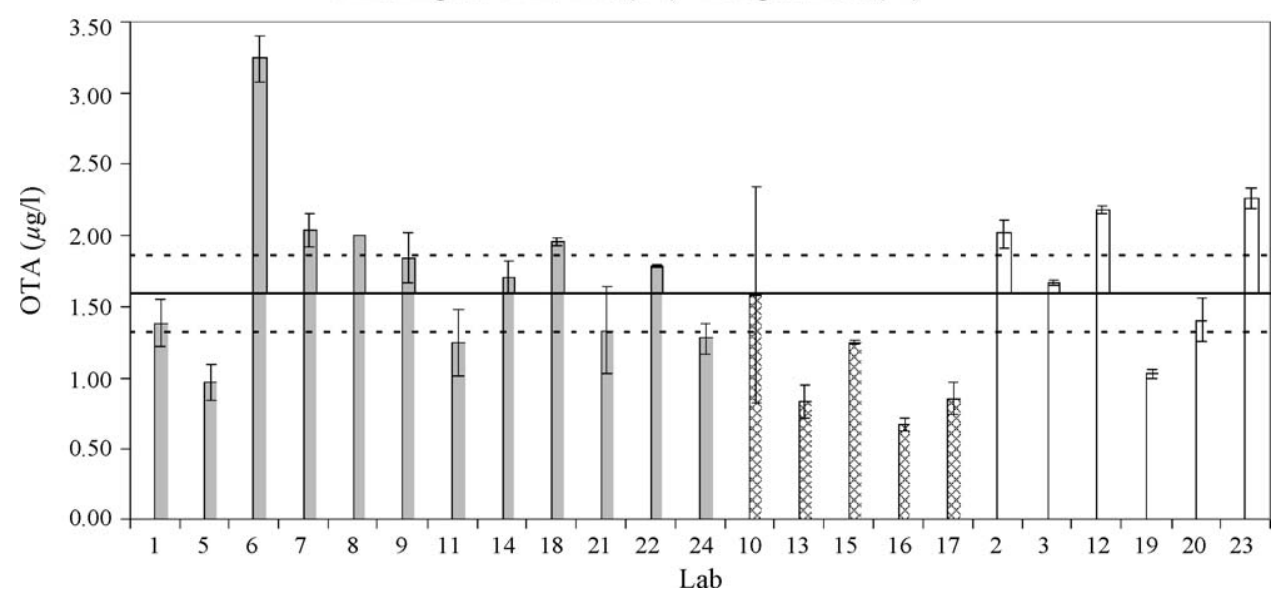

Fig. 4. White Liqueur Wine 16\% (v/v)_accepted labs (23).

cal methodologies were included and also because a different wine type was analyzed. Even so, if the EN 14133 group is considered separately and without its outlier (lab 4), the R.S.D. is closer $(20.0 \%)$ to the one in the standard.

\subsection{White Liqueur Wine $(16 \%, v / v)$}

In Table 5 the different statistical parameters for all laboratories, for White Liqueur Wine samples, are shown. One outlier is referred, by the Cochran test.

Table 6

Statistical parameters regarding OTA quantification, for Red Fortified Wine samples (spiked)

\begin{tabular}{|c|c|c|c|c|c|c|c|}
\hline Laboratory & Assay $1(\mu \mathrm{g} / \mathrm{l})$ & Assay $2(\mu \mathrm{g} / \mathrm{l})$ & Assay $3(\mu \mathrm{g} / \mathrm{l})$ & Method & Mean $(\mu \mathrm{g} / \mathrm{l})$ & Standard deviation & $z$-Score \\
\hline 1 & 2.24 & 2.85 & 2.71 & EN 14133 & 2.60 & 0.32 & -0.1 \\
\hline 2 & 2.84 & 2.83 & 2.86 & SPE-HPLC/FD & 2.84 & 0.02 & 0.1 \\
\hline 3 & 3.44 & 3.54 & 3.49 & MIP-SPE-HPLC/FD & 3.49 & 0.05 & 0.7 \\
\hline 4 & 4.50 & 4.46 & 5.63 & PBS-IAC-HPLC/FD & 4.86 & 0.66 & 2.0 \\
\hline 5 & 2.34 & 2.29 & 2.29 & EN 14133 & 2.31 & 0.03 & -0.4 \\
\hline 6 & 5.22 & 4.84 & 3.87 & EN 14133 & 4.64 & 0.70 & 1.8 \\
\hline 7 & 3.20 & 3.30 & 3.50 & EN 14133 & 3.33 & 0.15 & 0.6 \\
\hline 8 & 1.60 & 1.60 & 1.60 & EN 14133 & 1.60 & 0.00 & -1.1 \\
\hline 9 & 3.89 & 3.25 & 3.60 & EN 14133 & 3.58 & 0.32 & 0.8 \\
\hline 10 & 2.55 & 2.63 & 2.60 & PBS-IAC-HPLC/FD & 2.59 & 0.04 & -0.1 \\
\hline 11 & 2.00 & 1.63 & 2.80 & EN 14133 & 2.14 & 0.60 & -0.6 \\
\hline 12 & 2.78 & 2.87 & 2.77 & DI-IS-HPLC & 2.81 & 0.06 & 0.1 \\
\hline 13 & 1.50 & 1.26 & & PBS-IAC-HPLC/FD & 1.38 & 0.17 & -1.3 \\
\hline 14 & 2.63 & 2.55 & 2.45 & EN 14133 & 2.54 & 0.09 & -0.2 \\
\hline 15 & 1.32 & 1.48 & 1.48 & PBS-IAC-HPLC/FD & 1.43 & 0.09 & -1.2 \\
\hline 16 & 1.10 & 1.00 & 1.20 & PBS-IAC-HPLC/FD & 1.10 & 0.10 & -1.5 \\
\hline 17 & 2.21 & 1.87 & 1.69 & PBS-IAC-HPLC/FD & 1.92 & 0.26 & -0.8 \\
\hline 18 & 3.64 & 3.41 & 3.45 & EN 14133 & 3.50 & 0.12 & 0.7 \\
\hline 19 & 3.89 & 3.59 & 3.52 & SAX-LC/MS-MS & 3.67 & 0.20 & 0.9 \\
\hline 20 & 1.65 & 1.62 & & SPE-HPLC/PDA & 1.64 & 0.02 & -1.0 \\
\hline 21 & 2.06 & 2.72 & 2.31 & EN 14133 & 2.36 & 0.33 & -0.3 \\
\hline 22 & 3.33 & 3.39 & 3.47 & EN 14133 & 3.40 & 0.07 & 0.6 \\
\hline 23 & 4.30 & 3.70 & 3.90 & SPE-HPLC/FD & 3.97 & 0.31 & 1.2 \\
\hline \multirow[t]{10}{*}{24} & 2.16 & 1.87 & 1.65 & EN 14133 & 1.89 & 0.26 & -0.8 \\
\hline & & & & Accepted laboratories & & 24 out of 24 & \\
\hline & & & & General mean & & 2.73 & \\
\hline & & & & Standard deviation of the general mean & & 1.02 & \\
\hline & & & & Relative standard deviation (\%) & & 37.43 & \\
\hline & & & & Maximum value (accepted laboratories) & & 4.86 & \\
\hline & & & & Minimum value (accepted laboratories) & & 1.10 & \\
\hline & & & & $s_{\mathrm{L}}$ (interlaboratorial standard deviation) & & 0.96 & \\
\hline & & & & $s_{\mathrm{r}}$ (repeatability standard deviation) & & 0.28 & \\
\hline & & & & $s_{\mathrm{R}}$ (reproducibility standard deviation) & & 1.00 & \\
\hline
\end{tabular}




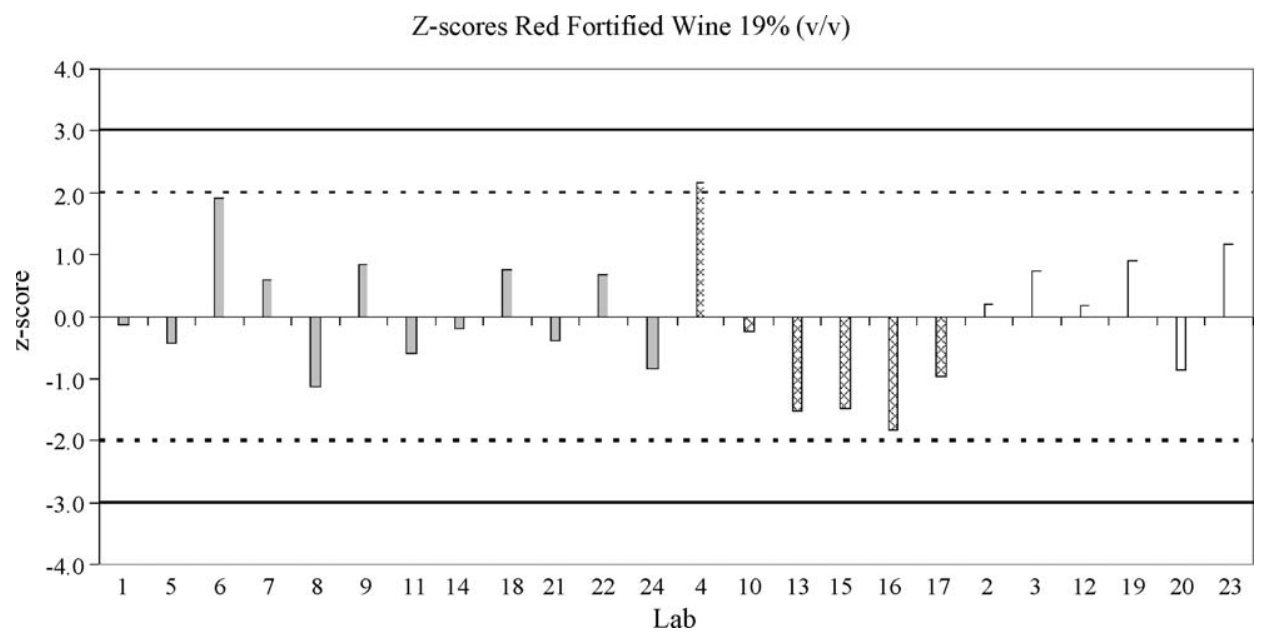

Fig. 5. $z$-Scores Red Fortified Wine 19\% (v/v).

For these samples, only one laboratory was excluded. The general mean of the accepted ones was $1.59 \mu \mathrm{g} / \mathrm{l}$, with R.S.D. of $36.79 \%$, somewhat higher than for the White Wine samples, with a much lower alcohol content.

Fig. 3 illustrates the $z$-scores for all laboratories, with the same grouping by method, before the outlier tests (mean $=1.75 \mu \mathrm{g} / \mathrm{l})$.

Again, the outlier (lab 4) had the worst result and was considered incorrect according to the $z$-scores test. The most sensible variability seems to happen in the PBS-IAC-HPLC/FD group. When removing the outlier, the mean values match the parameters of Table 5, and these findings are confirmed, both in number of laboratories with results outside the confidence intervals and in the deviation of the individual group mean from the general mean $(-34.8 \%$, followed by other methods with $+10.8 \%$ and EN 14133 with 8.8\%), as seen in Fig. 4.

There is no information concerning other collaborative studies with this type of wines and therefore results for reproducibility could not be compared, assuming that the "white wines" analyzed in the European Standard 14133 [24] are not liqueurs.

\subsection{Red Fortified Wine (19\%, v/v)}

For Red Fortified Wine samples, the different statistical parameters for all laboratories can be seen in Table 6 . No outliers were found in this case.

The general mean of all laboratories was $2.73 \mu \mathrm{g} / \mathrm{l}$, with R.S.D. similar to White Liqueur Wine (37.43\%). In the study depicted in the European Standard EN 14133 [24], red wines yielded a value of $12.9 \%$ R.S.D., but again probably dealing with different types of wine, namely regarding sugar and alcohol content and acidity. Considering the EN 14133 group separately, the R.S.D. (30.9\%) approaches, although to a lesser extent than for White Wine, the one in the standard. Nevertheless, these samples, which had the highest alcohol content (19\%), were the most consistent, when subjected to the statistical tests.

Fig. 5 shows the $z$-scores for all laboratories, grouped by methods. Although having no outliers, lab 4 had the worst result, but was only qualified as questionable, according to the $z$-scores screening. The trends found for the White Liqueur Wine samples were confirmed in this case, as the PBS-IAC-HPLC/FD method group mean was the most deviant comparing to the general mean $(-18.9 \%$, followed by other methods with $+12.4 \%$ and EN 14133 with $+3.4 \%$ ).

\subsection{Overall results and quality assurance of the study}

AOAC demands specific requirements for laboratory validation of chemical methods [47]. The protocol for interlaboratory studies requires the use of a minimum of eight laboratories and the acceptable range for the methods variability by the Horrat index may provide useful information to assure the quality of the study.

The Horrat index $\left(\mathrm{HORRAT}_{\mathrm{R}}\right)$ is defined as the ratio between the values found for the R.S.D. (\%) of the reproducibility and the R.S.D. (\%) calculated from the Horwitz equation [48]. Acceptable values of this ratio are typically $0.5-2$.

HORRAT $_{R}=\frac{\text { R.S.D.R }(\text { found) }}{\text { R.S.D.H }(\text { Horwitz) }}$

The Horwitz equation was statistically derived from data of more than 10,000 collaborative studies [49], and even considering the inherent limitations from the differences between analytes, methods or matrices are not strictly accounted for, it is a valuable estimation when interlaboratory studies cannot be provided. The R.S.D. calculation form the Horwitz equation is R.S.D.H $=2^{(1-0.5 \log C)}$, where $C$ is the concentration of the analyte in the sample as a decimal fraction, such as $1 \mathrm{mg} / \mathrm{kg}=10^{-6}$.

Table 7 presents the Horrat index evaluated in this study and the one calculated for the results published in the European Standard 14133. Horrat indexes in this study were, on average, within the recommended range and it should be noticed that its evaluation supposes the same analytical methodology. However, the evaluation for the results of the laboratories that strictly used the EN 14133 in the present study was slightly higher, reaching the maximum recommended of 2 , on average, with a value above that limit for the Red Liqueur Wine samples (2.7). The average Horrat index calculated using the results published in 
Table 7

The Horrat index calculated from the Horwitz equation and the Horwitz equation corrected by Thompson

\begin{tabular}{|c|c|c|c|c|c|c|}
\hline \multirow[t]{2}{*}{ Wine type } & \multicolumn{2}{|c|}{ OTA concentration } & \multirow[t]{2}{*}{ R.S.D. found (\%) } & \multirow[t]{2}{*}{ R.S.D. Horwitz (\%) } & \multirow[t]{2}{*}{ Horrat index (Horwitz) } & \multirow[t]{2}{*}{ Horrat index (Thompson) } \\
\hline & $\mu \mathrm{g} / 1$ & $\%$ & & & & \\
\hline \multicolumn{7}{|c|}{ All analytical methods included (this study, 24 labs) } \\
\hline White & 1.96 & 0.000020 & 27.3 & 20.3 & 1.3 & 1.2 \\
\hline White liqueur & 1.59 & 0.000016 & 36.8 & 20.9 & 1.8 & 1.7 \\
\hline Red liqueur & 2.73 & 0.000027 & 37.4 & 19.3 & 1.9 & 1.7 \\
\hline Average & & & & & 1.7 & 1.5 \\
\hline \multicolumn{7}{|c|}{ EN 14133 (this study, 12 labs) } \\
\hline White & 2.37 & 0.000024 & 31.8 & 19.7 & 1.6 & 1.4 \\
\hline White liqueur & 1.73 & 0.000017 & 34.2 & 20.7 & 1.7 & 1.6 \\
\hline Red liqueur & 2.14 & 0.000021 & 53.1 & 20.0 & 2.7 & 2.4 \\
\hline Average & & & & & 2.0 & 1.8 \\
\hline \multicolumn{7}{|c|}{ Results extracted from EN 14133 [21] (16 labs) } \\
\hline White & 0.105 & 0.000001 & 15.9 & 31.5 & 0.5 & 0.7 \\
\hline White & 0.998 & 0.000010 & 13.3 & 22.4 & 0.6 & 0.6 \\
\hline White & 1.764 & 0.000018 & 13.1 & 20.6 & 0.6 & 0.6 \\
\hline White & 0.283 & 0.000003 & 14.6 & 27.1 & 0.5 & 0.7 \\
\hline Red & 0.186 & 0.000002 & 11.9 & 28.9 & 0.4 & 0.5 \\
\hline Red & 0.813 & 0.000008 & 12.5 & 23.2 & 0.5 & 0.6 \\
\hline Red & 2.53 & 0.000025 & 13.6 & 19.5 & 0.7 & 0.6 \\
\hline Red & 1.69 & 0.000017 & 13.6 & 20.7 & 0.7 & 0.6 \\
\hline Average & & & & & 0.6 & 0.6 \\
\hline
\end{tabular}

the EN 14133 standard is within the range of acceptance of the reproducibility (0.6).

There could be two main reasons for these punctual deviations. The first is that the level of training and experience as well as quality assurance/quality control $(\mathrm{QA} / \mathrm{QC})$ procedures was not discriminated among the laboratories, giving a more realistic view of the worldwide production of OTA results. The second is that wines different from those for which the standard was validated were chosen and matrix effects can be important, probably not affecting significantly the accuracy of the methodology but increasing the interlaboratorial variability. It should also be mentioned that the Horwitz approach has its limitations and is not unquestionably accepted, as reported by Ritter et al. [50] for analysis in plastics and by van der Veen [51] in doping control in sport, which pointed towards a possible underestimation of the uncertainty. Furthermore, Thompson [52] stated that this expression could not be valid in all cases, proposing some modifications for the highest and the lowest concentration ranges, with the following expressions in terms of $\sigma_{\mathrm{R}}$ (standard deviation of the reproducibility):

$\sigma_{\mathrm{R}}=0.22 C, \quad$ for $C<1.2 \times 10^{-7}$

(in mass fraction, which corresponds to $120 \mathrm{mg} / \mathrm{kg}$ )

$\sigma_{\mathrm{R}}=0.02^{(1-0.5 \log C)}, \quad$ for $<1.2 \times 10^{-7} \leq C \leq 0.138$

(the Horwitz equation, in absolute value)

$\sigma_{\mathrm{R}}=0.01 C^{0.5}, \quad$ for $C>0.138$

(in mass fraction, which corresponds to $138 \mathrm{~g} / \mathrm{kg}$ )
The ranges of this study fall under the first expression, which forecasts a value of R.S.D. of $22 \%$. Correcting the Horrat index under this assumption, the results are slightly better, as can be seen in Table 7. There is only one value outside the recommended range (Red Liqueur Wine for EN 14133, with 2.4) and the average values for the three situations studied fall clearly within that range (1.5, 1.8 and 0.6 for all laboratories, laboratories employing EN 14133 in this work and results reported in the European Standard EN 14133, respectively).

Taking into account that the current study rather than validate one method aims to compare different methods for the same analytic quantification, which is more prone to some inconsistencies, as stated by Lisinger et al. [53], the worldwide and method-free character of the work could have caused additional problems. Instead, the results show that, in this case and despite all their possible sources, they can be meaningless, supporting the reliability of the conclusions.

\section{Conclusions}

The participation of a large number of laboratories (24), from almost all continents of the world was very important to have a general assessment of the current methods employed to analyze ochratoxin A in wines and their global performance. As was seen, the results were consistent, with low variability amongst different laboratories. In the three sample types, only two outliers (White Wine), one (White Liqueur Wine) and none (Red Fortified Wine) were found, when the maximum number of laboratories that could be excluded was five.

When comparing the results by methods, the differences were not very clear, meaning that the use of different methods had no 
relation with the global variability. Even the use of methods so distinct from the standard EN 14133 such as LC/MS-MS did not present significant variability. When comparing the individual mean of each group with the global mean for each wine, the six laboratories adopting the PBS-IAC-HPLC/FD approach were the ones showing the most deviant behaviour and the lowest values in OTA content. If we report to the number of laboratories with results outside the confidence intervals, the EN 14133 and the PBS-IAC-HPLC/FD share the least accomplished results. However, these findings cannot constitute a rule of statistical significance, due to the overall proximity between the results of all groups. Furthermore, it should be pointed out that the EN 14133 and the PBS-IAC-HPLC/FD approaches have in common the use of immunoaffinity columns, which may contribute to a rise in the variability of the results, either by its production process or the experience of the operator.

The choice of three different types of wine to analyze, with distinct alcohol contents $(10.5 \%, 16 \%$ and $19 \%)$ meant to test even further the flexibility of the OTA analysis. The most noticeable aspect was the fact that the relative standard deviation of the laboratories means (without outliers) was lower in the first case (White Wine, 27.30\%) than in the other two (White Liqueur Wine and Red Fortified Wine, with $36.49 \%$ and $37.43 \%$, respectively). It is, however, difficult to assume indisputably that the alcohol content is directly linked to this phenomenon. Considering the results of the EN13144 group alone, the R.S.D. are closer to the ones referred in the European Standard, especially for White Wine (20.0\% versus $14.3 \%$ ). The average Horrat index ( 1.7 with the Horwitz equation and 1.5 after correction by Thompson) fell within the range recommended by the AOAC for the quality assurance of collaborative studies (0.5-2).

It can be safely stated that all the overall results yielded by this Interlaboratory Study were very good. Only two laboratories (labs 4 and 6) produced outliers at some point, and were removed from the statistical analysis when such event took place. The analysis and quantification of OTA is, therefore, reproducible worldwide, for the type of wine samples included in this work.

\section{Acknowledgments}

LEPAE/FEUP and ALABE wish to acknowledge the financial support of the INIAP (Portugal), through the Program AGRO, contract number 255 and the effort and cooperation of all participant laboratories and people involved in this interlaboratory study.

\section{References}

[1] B. Zimmerli, R. Dick, J. Chromatogr. B 666 (1995) 85.

[2] Office International de la Vigne et du Vin (OIV), Reduction de L'Ochratoxine A dans les Vins, Resolution CST 1/2002, Paris, France, 2002.

[3] Commission regulation (EC) no. 123/2005 of 26 January 2005 amending regulation (EC) no. 466/2001 as regards ochratoxin A, Off. J. Eur. Union L25 (2005) 3.

[4] E.E. Creppy, J. Toxicol.-Toxin Rev. 18 (1999) 273.

[5] M. Ospital, J.-M. Cazabeil, A.-M. Betbeder, C. Tricard, E. Creppy, B. Medina, Ver. Fr. Oenol. 169 (1998) 16.
[6] Y. Ueno, Mycotoxins 47 (1998) 25.

[7] S. MacDonald, P. Wilson, K. Barnes, A. Damant, R. Massey, E. Mortby, M.J. Shepherd, Food Addit. Contam. 16 (1999) 253.

[8] I. Festas, P. Herbert, L. Santos, M. Cabral, P. Barros, A. Alves, Am. J. Enol. Vitic. 51 (2000) 150.

[9] N. Ratola, L. Martins, A. Alves, Anal. Chim. Acta 513 (2004) 319.

[10] A. Pietri, T. Bertuzzi, L. Pallaroni, G. Piva, Food. Addit. Contam. 18 (2001) 647.

[11] R. Saelzer, M. Vega, A. Retamal, G. Ríos, E. Herlitz, Noticias Técnicas del Laboratório 2 (2002) 6.

[12] E.H. Soufleros, C. Tricard, E.C. Bouloumpasi, J. Sci. Food Agric. 83 (2003) 173.

[13] G.S. Shephard, A. Fabiani, S. Stockenström, N. Mshicileli, V. Sewram, J. Agric. Food Chem. 51 (2003) 1102.

[14] N. Bellí, S. Marín, A. Duaigües, A.J. Ramos, V. Sanchis, J. Sci. Food Agric. 84 (2004) 591.

[15] J. Blesa, J.M. Soriano, J.C. Moltó, J. Mañes, J. Chromatogr. A 1054 (2004) 397.

[16] C.A.R. Rosa, C.E. Magnoli, M.E. Fraga, A.M. Dalcer, D.M.N. Santana, Food Addit. Contam. 21 (2004) 358.

[17] G.J. Soleas, J. Yan, D.M. Goldberg, J. Agric. Food Chem. 41 (2001) 2733

[18] J. Varga, Z. Kozakiewicz, Trends Food Sci. Technol. 17 (2006) 72.

[19] A. Leitner, P. Zöllner, A. Paolillo, J. Stroka, A. Papadopoulou-Bouraoui, S. Jaborek, E. Anklam, W. Lindner, Anal. Chim. Acta 453 (2002) 33.

[20] J.M. Sáez, Á. Medina, J.V. Gimeno-Adelantado, R. Mateo, M. Jiménez, J. Chromatogr. A 1029 (2004) 125.

[21] P. Zöllner, A. Leitner, D. Lubda, K. Cabrera, W. Lindner, Chromatographia 804 (2000) 818.

[22] M. Reinsch, A. Töpfer, A. Lehmann, I. Nehls, U. Panne, Food Chem. 100 (2007) 312-317.

[23] N.M. Maier, G. Buttinger, S. Welhartizki, E. Gavioli, W. Lindner, J. Chromatogr. B 804 (2004) 103.

[24] European Committee for Standardization (CEN), Foodstuffs - determination of ochratoxin A in wine and beer - HPLC method with immunoaffinity column clean-up, EN 14133:2003, Brussels, Belgium, 2003.

[25] Association of Official Analytical Chemists (AOAC), Determination of ochratoxin A in wine and beer, Official Method 2001.01, AOAC International, 2002.

[26] J.L. Moreira, A.M. Marcos, P. Barros, Ciência Téc. Vitiv. 17 (2002) 41.

[27] S.M. Abreu, A. Alves, B. Oliveira, P. Herbert, Anal. Bioanal. Chem. 382 (2005) 498.

[28] ISO Guide 43:1997, Proficiency testing by interlaboratory comparisons, International Organization for Standardization, Genève, Switzerland, 1997.

[29] Accessed on 30/12/2005 http://www.bipea.org/en/essais.htm.

[30] C. Lindig, Chemosphere 37 (1998) 405.

[31] M. Farré, F. Arranz, J. Ribó, D. Barceló, Talanta 62 (2004) 549.

[32] R. Hoogerbrugge, S.M. Gort, E.G. van der Velde, P. Van Zoonen, Anal. Chim. Acta 388 (1999) 119.

[33] A.H. Garde, Å.M. Hansen, T.B. Nikolajsen, Accred. Qual. Assur. 8 (2003) 16.

[34] T.F. Bidleman, S. Cussion, L.M. Jantunen, Atmos. Environ. 38 (2004) 3713

[35] E. Eljarrat, M. Guillamón, J. Seuma, B.B. Mogensen, I.S. Fomsgaard, A. Olivero-Bastidas, F.A. Macías, A. Stochmal, W. Oleszek, O. Shakaliene, D. Barceló, J. Chromatogr. A 1047 (2004) 69.

[36] J. van Loco, S.P.J. van Leeuwen, P. Roos, S. Carbonnelle, J. de Boer, L. Goeyens, H. Beernaert, Talanta 63 (2004) 1169.

[37] J.-P. Villeneuve, S. de Mora, C. Cattini, Trends Anal. Chem. 23 (2004) 469.

[38] F.J. Santos, E. Barceló-Barrachina, F. Toribio, L. Puignou, M.T. Galceran, E. Persson, K. Skog, C. Messner, M. Murkovic, U. Nabinger, A. Ristic, J. Chromatogr. B 802 (2004) 69.

[39] E. Hund, D.L. Massart, J. Smeyers-Verbeke, Anal. Chim. Acta 423 (2000) 145.

[40] ISO 5725:1994, Accuracy (trueness and precision) of measurement methods and results, International Organization for Standardization, Genève, Switzerland, 1994.

[41] H. van der Voet, J.A. van Rhijn, H.J. van de Wiel, Anal. Chim. Acta 391 (1999) 159. 
[42] I. Taverniers, E. van Bockstaele, M. de Loose, Trends Anal. Chem. 23 (2004) 490.

[43] P. Dehouck, Y. Vander Heyden, J. Smeyers-Verbeke, D.L. Massart, R.D. Marini, P. Chiap, P. Hubert, J. Crommen, W. Van de Wauw, J. De Beer, R. Cox, G. Mathieu, J.C. Reepmeyer, B. Voigt, O. Estevenon, A. Nicolas, A. Van Schepdael, E. Adams, J. Hoogmartens, J. Chromatogr. A 1010 (2003) 63.

[44] G. Becher, L.S. Haug, C. Thomsen, Talanta 63 (2004) 1122.

[45] N. Boley (Ed.), EURACHEM Guide, Selection, Use and Interpretation of Proficiency Testing (PT) Schemes by Laboratories, 1.0th ed., EURACHEM, Teddington, UK, 2002.

[46] Y. vander Heyden, J. Saevels, E. Roets, J. Hoogmartens, D. Decolin, M.G. Quaglia, W. van den Bossche, R. Leemans, O. Smeets, F. van de Vaart, B.
Mason, G.C. Taylor, W. Underberg, A. Bult, P. Chiap, J. Crommen, J. de Beer, S.H. Hansen, D.L. Massart, J. Chromatogr. A 830 (1999) 3.

[47] W. Horwitz, AOAC requirements for single laboratory validation of chemical methods, Draft 2002-11-07, AOAC, 2002 (accessed on 30/12/2005) http://www.aoac.org/Ag_Materials/additives/aoac_slv.pdf.

[48] W. Horwitz, Anal. Chem. 54 (1982) 67A.

[49] W. Horwitz, J. AOAC Int. 86 (2003) 109.

[50] A. Ritter, V.R. Meyer, Polym. Test. 24 (2005) 988.

[51] A.M.H. van der Veen, Accred. Qual. Assur. 8 (2003) 334.

[52] M. Thompson, Analyst 125 (2000) 2020.

[53] T.P.J. Lisinger, W. Kandler, R. Krska, M. Grasserbauer, Accred. Qual. Assur. 3 (1998) 322 